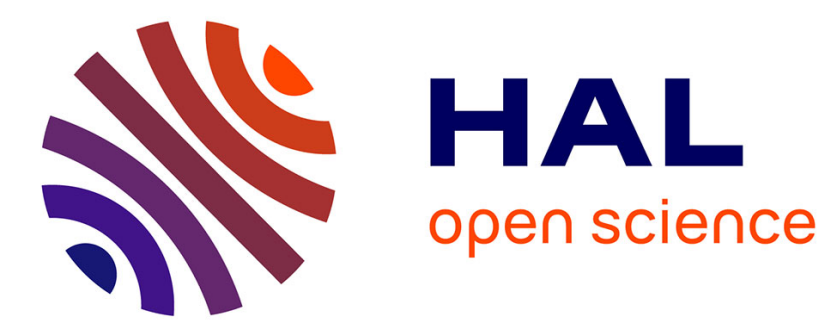

\title{
Hierarchical Porosity in Silica Thin Films by a One-Step Templating Strategy Using a Stimuli-Responsive Bioderived Glycolipid
}

\author{
Niki Baccile, Thomas Fontecave, Cédric Boissière, Inge van Bogaert
}

\section{To cite this version:}

Niki Baccile, Thomas Fontecave, Cédric Boissière, Inge van Bogaert. Hierarchical Porosity in Silica Thin Films by a One-Step Templating Strategy Using a Stimuli-Responsive Bioderived Glycolipid. Journal of Physical Chemistry C, 2013, 117 (45), pp.23899-23907. 10.1021/jp409529j . hal-01455140

\section{HAL Id: hal-01455140 \\ https://hal.sorbonne-universite.fr/hal-01455140}

Submitted on 3 Feb 2017

HAL is a multi-disciplinary open access archive for the deposit and dissemination of scientific research documents, whether they are published or not. The documents may come from teaching and research institutions in France or abroad, or from public or private research centers.
L'archive ouverte pluridisciplinaire HAL, est destinée au dépôt et à la diffusion de documents scientifiques de niveau recherche, publiés ou non, émanant des établissements d'enseignement et de recherche français ou étrangers, des laboratoires publics ou privés. 
IMPORTANT NOTE : Please be aware that slight modifications occurring after Proof correction may occur between this version of the manuscript and the version on the Publisher's website

\title{
Hierarchical Porosity in Silica Thin Films by a One-Step Templating Strategy using a Stimuli-Responsive Bioderived Glycolipid
}

\author{
Authors

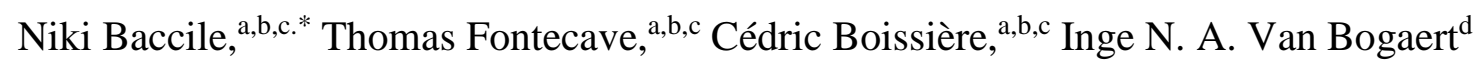

\begin{abstract}
Affiliations
a-UPMC Univ Paris 06, UMR 7574, Chimie de la Matière Condensée de Paris, F-75005, Paris, France

b- CNRS, UMR 7574, Chimie de la Matière Condensée de Paris, F-75005, Paris, France

c- Collège de France, UMR 7574, Chimie de la Matière Condensée de Paris, F-75005, Paris, France

d - InBio, Department of Biochemical and Microbial Technology, Faculty of Bioscience Engineering, Ghent University, Coupure Links 653, 9000, Ghent, Belgium

* Corresponding author: Laboratoire de Chimie de la Matière Condensée de Paris, Collège de France, 11, Place M. Berthelot, 75005, Paris (France). Tel. +33 1442715 44; E-mail: niki.baccile@upmc.fr
\end{abstract}




\section{ABSTRACT}

Hierarchical porosity in thin films obtained with the Evaporation Induced Self-Assembly strategy is a major challenge that is generally accomplished by combining different templating compounds or strategies, each one typical for a given size range. For instance, for small-medium sized pores (below $20 \mathrm{~nm}$ ) a library of surfactants exists, while colloids, polymers, as well as phase separation and water condensation strategies are used for large mesopores to macropores (up to several microns). Here, we report the $\mathrm{pH}$-dependant templating effect using a class of entirely bioderived, functional, glycolipids obtained from the culture broth of the yeast Starmerella bombicola. We show that these compounds can be used to achieve a micro-to-macro hierarchical porosity in a one-step process by simply tuning the solution $\mathrm{pH}$ and without using any additional co-surfactant, co-solvent or pore-swelling agent. SAXS, TEM, SEM and ellipsoporosimetry data show the multi-scale porous texture of silica thin films. We attribute this behaviour to the unusual self-assembling properties of these compounds as a function of $\mathrm{pH}$ and which varies, at the same surfactant concentration, from dispersed micelles to micronic aggregates. 


\section{INTRODUCTION}

The synthesis of porous silica-based materials obtained by a bottom-up, chemistrybased process (gels, powders, thin films, fibbers) represents an exciting challenge for many applications like catalysis, sensing and drug delivery, in which a large specific surface area is

a crucial characteristic. ${ }^{1,2,3}$ So far, the developed strategies introduce either monomodal micro $(<2 \mathrm{~nm})$, meso $(2-50 \mathrm{~nm})$, macro $(>50 \mathrm{~nm})$ or multiscaled porosity at once. Independently on the scale, one common goal has always been the development of an efficient strategy to achieve the three-dimensional, long-range organisation of the pores, even if rather than order, hierarchy in size and pore interconnection have recently been judged the most important parameters for the improvement of diffusion, percolation or adsorption phenomena within a material. ${ }^{4,5}$ In the field of multifunctional thin films, the hierarchical distribution of pores is very important, for instance, to develop highly performing sensors (both chemo- and bio-) and catalytic surfaces. More specifically, extensive work has been performed to achieve a multiscale porosity on thin films obtained by the sol-gel process and a recent review paper, to which we direct the reader for more details, makes a nice summary of such a field of research. Leaving aside all physical, top-down methods that use high-energy beams or chemical etching, a short point on the various types of templating strategies from the smallest to the largest pore sizes is presented hereafter. Micropores $(<2 \mathrm{~nm})$ are obtained using small molecules, such as quaternary ammonium salts or ionic liquids. Mesoporosity $(2-50 \mathrm{~nm})$ is generally achieved using surfactants (cationic or non-ionic), where the pore size is generally related to the surfactant dimensions. Quaternary ammonium or sulfates-based surfactants provide small mesopores while block-copolymers, the size of which is tunable at will (though at high cost), is generally in charge for the larger mesopores up to about 20-30 nm. Surfactants are also well-known to provide a long range mesoscopic order. The region between large mesopores and small macropores $(30-100 \mathrm{~nm})$ is probably the most challenging 
one. The easiest way to obtain such pore sizes is to use either organic or inorganic nanoparticles (colloidal silica, mesoporous or not, polystyrene and polymethylmethacrylate beads) and in some cases unshaped polymers like polyethylene or polypropylene glycole (PEG, PPG). Above $100 \mathrm{~nm}$, other methods exist: large-scale phase separation of polymers, use of salts crystals, water droplets, decomposition gases and ice-templating. Each one of these methods is summarized in Table 1, where, for sake of clarity, we disregard the nature of the inorganic support, which is most often composed of $\mathrm{SiO}_{2}$ or $\mathrm{TiO}_{2}$. The combination of two or more approaches eventually produces very impressive hierarchical materials. Yang et al. ${ }^{6}$ have for instance used block copolymers and latex spheres in combination with micromolding to obtain materials with long range porous order in the $10 \mathrm{~nm}$ to $\mu \mathrm{m}$ size range. In the same line but using a different physico-chemical approach, Malfatti et al. ${ }^{7}$ have combined the use of block copolymers with polymer-induced porosity enhancement by swelling and phase separation to make titania thin films with bimodal porosity between 10 and $150 \mathrm{~nm}$, a range which is notoriously difficult to achieve with standard templating methods.

Table 1. Most Common Bottom-up Porogenic Strategies Employed for Sol-Gel Derived Thin Films (mostly, but not limited to, $\mathrm{SiO}_{2}$ and $\mathrm{TiO}_{2}$ ) The size domains are indicative. Additional information can be found in ref. 4.

\begin{tabular}{clc}
\hline Size (nm) & \multicolumn{1}{c}{ Strategy } & $\begin{array}{c}\text { Example } \\
\text { reference }\end{array}$ \\
\hline$<2$ & Small molecules (e.g., ionic liquids) & 8 \\
$2-6$ & $\begin{array}{l}\text { Surfactants: ionic (e.g., CTAB, SDS), small block } \\
\text { copolymers (e.g., Brij) }\end{array}$ & 9,10 \\
& Surfactants: large block copolymers (e.g., Pluronics, & 10,11 \\
$6-20$ & KLE, PB-PEO, PS-PEO) & 12,13 \\
& Nanoparticles and small colloids (inverse opal strategy) & 14 \\
$20-100$ & Polymers (e.g., PEG, PPG) & 15 \\
& Salt crystals & 16,17 \\
& Polymer phase separation (e.g., PEG, PLA) & 18 \\
& Water (ice) & 19,20 \\
& Water/volatile solvents (“breath figures”) & 21 \\
& Large colloids (inverse opal strategy) & 22 \\
\hline
\end{tabular}


A close look at Table 1 indicates that the medium and large ranges of porosities (6-20 $\mathrm{nm}$ ) cannot be achieved with a surfactant templating strategy due to the obvious size-limiting factors, unless laborious and expensive organic synthesis provides well-designed block copolymers. For this reason, polymers, polymeric (or inorganic) colloids or those other strategies listed in Table 1 must be used. In addition, if one wishes to introduce ecoconception criteria (e.g., non-toxic materials, renewable resources, biodegradability) in the material synthesis process, as recently outlined in various works, ${ }^{23,24}$ most of these approaches should probably be revised and substituted by others.

In this work we would like to show the porogenic effect of a single biosurfactant at multiple scales. We have previously reported that acidic sophorolipids (SL), a family of entirely bio-derived glycolipids with low environmental impact, ${ }^{25,26,27,28,29}$ can be used as structure-directing agent for silica thin films ${ }^{30}$ using the evaporation induced self-assembly (EISA) process. ${ }^{9}$ In that work, we have shown the possibility to obtain small mesopores under acidic conditions. Here, we go much further as we show that by tuning the initial conditions (concentration, $\mathrm{pH}$ ), it is possible to obtain an interconnected porous network between $1 \mathrm{~nm}$ and $1 \mu \mathrm{m}$. The most striking point is that the largest pores seem to be related to the peculiar assembling properties of SLs; in fact, we do not use any additive (block copolymers, polymers, colloids) nor any highly volatile solvent (THF, chloroform). Indeed, we have shown that SL display an unusual pH-dependent self-assembly behaviour and, in particular above $\mathrm{pH}=10$, most micelles are disrupted in favour of micronic aggregates, ${ }^{31,32}$ which we believe to be the origin of the multi-scale porogenic effect. In summary, this work shows that by exploiting the self-assembly properties of a single, bioderived, glycolipid it is possible to achieve a hierarchical porosity within thin silica films.

\section{EXPERIMENTAL METHODS}


Sample Preparation. The synthesis of acidic sophorolipids (Figure 1) was described in Ref. 31. Mesoporous silica thin films are prepared by dip-coating via the EISA technique. Tetraethyl orthosilicate (TEOS), ethanol (EtOH), concentrated $\mathrm{HCl} 37 \%$ and $\mathrm{NaOH}$ are purchased from Aldrich and used without further purification. An initial pre-hydrolyzed TEOS solution is prepared as follows: $0.53 \mathrm{~mL}$ of TEOS, $0.37 \mathrm{~mL}$ EtOH and $40 \mu \mathrm{L}$ of a 0.77 $\mathrm{M} \mathrm{HCl}$ solution. This solution is stirred for $45 \mathrm{~min}$ and then $1.86 \mathrm{~mL}$ of $\mathrm{EtOH}, 0.19 \mathrm{~mL}$ of water, $50 \mu \mathrm{L}$ of $1 \mathrm{M} \mathrm{HCl}$ are added. The amount of acidic sophorolipids (SL) ranges from $0.088 \mathrm{~g}$ to $0.266 \mathrm{~g}$, which corresponds to a SL/TEOS ratio ranging from 0.06 to 0.18 . This is stirred for 15 min before dip-coating. Silicon substrates (thickness $400 \mu \mathrm{m}$ ) are dip-coated at constant relative humidity $(\approx 19-22 \%)$, the pulling rate is set at a variable speed ranges from to $1.9 \mathrm{~mm} . \mathrm{s}^{-1}$ to $1.4 \mathrm{~mm} . \mathrm{s}^{-1}$. Finally, after deposition, films are treated at $130{ }^{\circ} \mathrm{C}$ for one night to consolidate the silica scaffold and then calcined at $350{ }^{\circ} \mathrm{C}$ under air for $1 \mathrm{~h}$. Samples presented in the text correspond to the following amount of SL/TEOS molar ratio: $\mathrm{S} 1 \equiv 0.06$, $\mathrm{S} 2=0.08, \mathrm{~S} 3=0.10, \mathrm{~S} 4=0.12, \mathrm{~S} 5=0.14, \mathrm{~S} 6=0.16, \mathrm{~S} 7 \equiv 0.18$.

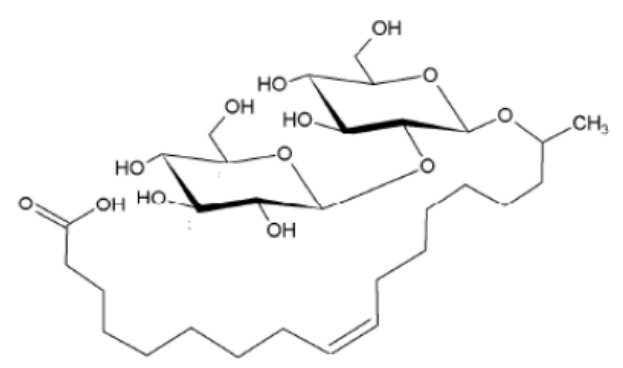

Figure 1. Molecular structure of acidic sophorolipids

The effect of $\mathrm{pH}$ was tested by adding micromolar amounts of a $1 \mathrm{M} \mathrm{NaOH}$ solution to the solution immediately before dip-coating, thus preventing its gelification. These specific samples are coded as such: $\mathrm{NaOH} \_0$, for which no base is added, $\mathrm{NaOH} \_1$ and $\mathrm{NaOH} \_2$, the $\mathrm{NaOH} / \mathrm{TEOS}$ molar ratio composition of which is given in Table 2. 
Table 2 - List of Samples with Values for Each Component Given in Molar

Ratios $\mathrm{NaOH} \_0, \mathrm{NaOH} \_1$ and $\mathrm{NaOH} \_2$ correspond to the sample codes used in this study and the values given indicate the molar amount of $\mathrm{NaOH}$ with respect to TEOS.

\begin{tabular}{ccccccc}
\hline Sample & SL & TEOS & NaOH_0 & NaOH_1 & NaOH_2 & NaOH/SL \\
\hline S1 & 0.06 & 1 & 0 & $1.69 \cdot 10^{-2}$ & $6.78 \cdot 10^{-2}$ & 1.1 \\
S5 & 0.14 & 1 & 0 & $1.69 \cdot 10^{-2}$ & $10.2 \cdot 10^{-2}$ & 0.7 \\
S7 & 0.18 & 1 & 0 & $1.69 \cdot 10^{-2}$ & $10.2 \cdot 10^{-2}$ & 0.6 \\
\hline
\end{tabular}

Experimental Techniques. Transmission Electron Microscopy (TEM) was run on a FEI Tecnai 120 Twin microscope operating at $120 \mathrm{kV}$ and equipped with a high resolution Gatan Orius CCD 4k x 4k numeric camera while Scanning Electron Microscopy (SEM) was done on a Hitachi S3400N instrument. Energy Dispersive X-ray Spectroscopy was done using an Oxford X-Max (area: $20 \mathrm{~mm}^{2}$ ) detector installed on the just described SEM instrument. Grazing incidence Small angle X-ray scattering (GISAXS) measurements on powder samples were performed on a pinhole type S-MAX 3000 RIGAKU Nanoviewer instrument using a monochromatic $\mathrm{Cu}-\mathrm{K} \alpha$ radiation and equipped with a CCD detector. The sample-to-detector distance was 0.059 meters. The applied voltage and filament current were $40 \mathrm{kV}$ and $50 \mathrm{~mA}$ respectively. Environmental Ellipsometric Porosimetry analyses were recorded with a M2000 Woolam ellipsometer. The sample was fixed in a controlled atmosphere cell in which the relative humidity was controlled by mass flow controllers. The analysis protocols and the setup are described in Reference 33. A simple Cauchy’s equation was used for modeling the optical properties of the porous thin films. The probe beam incidence angle was fixed at $70^{\circ}$. Dynamic Light Scattering (DLS) was run on a Zetasizer Nano ZS Malvern Instrument using the Zetasizer software for data acquisition and size distribution by intensity.

\section{RESULTS}

Effect of Sophorolipid Concentration The effect of increasing SL concentration (S1 to S7) on the mesophase formation with no base added (samples $\mathrm{NaOH} \_0$ in Table 1) is depicted in 
Figure 2, where the integrated SAXS patterns are shown in $\log (\mathrm{I})-\log (\mathrm{q})$ scale. A broad correlation peak, indicative of a wormlike structure and the position of which is related to the intermicellar distance, $d=2 \pi / q$, is observed for S1. Its intensity decreases from S1 to S7 and its position varies as follows: $\mathrm{d}_{\mathrm{s} 1}=5.23 \mathrm{~nm}, \mathrm{~d}_{\mathrm{s} 2}=4.58 \mathrm{~nm}, \mathrm{~d}_{\mathrm{s} 3}=4.24 \mathrm{~nm}, \mathrm{~d}_{\mathrm{s} 4}=4.08 \mathrm{~nm}, \mathrm{~d}_{\mathrm{s} 5}=$ $4.05 \mathrm{~nm}$ and $\mathrm{d}_{\mathrm{S} 6}=3.93 \mathrm{~nm}$. The $\mathrm{SL} / \mathrm{TEOS}=0.12$ ( $\mathrm{S} 4$ sample) seems to be the upper molar ratio limit above which the quality of the mesostructuration decreases. If compared with literature results, this value rather constitutes the lower range for silica; if compared to the system templated by the cationic CTAB surfactant, mesostructuration is kept up to surfactant/TEOS ratios as high as 0.35 , even if the $0.12-0.18$ can probably be considered to be the most stable interval. ${ }^{10}$ The difference can probably come from the difference in the occupied volume between the two compounds. In fact, sophorolipids contain a comparable C18 chain but a bulkier sophorose polar head group, thus making the expected volume fraction of incorporated surfactant lower. A similar case occurs for silica films templated by the larger Pluronic block-copolymers (typical molar mass are larger than $5000 \mathrm{Da}$ ), where the typical Pluronic/TEOS ratios are in the $0.001 / 0.030$ range. ${ }^{34,35}$ At SL/TEOS $=0.18$ (S7 sample), the correlation peak is replaced by a pronounced signal in the low-q region, characterized by a -1 slope of the scattered intensity in the $\log (\mathrm{I})-\log (\mathrm{q})$ spectrum (Figure $\mathrm{S} 1$ ). This value is typical for a cylindrical shape and a qualitative fit of the spectrum reveals the presence of channels, the typical geometrical parameters of which are: radius $=\sim 1 \mathrm{~nm}$, length $=\sim 7 \mathrm{~nm}$, as directly extracted from the fit shown in Figure S1 Such data can indicate the presence of elongated, most likely interconnected, micropores. We will only consider in the following part of the work a selected set of data concerning samples S1, S5 and S7, which are representative of the $\mathrm{pH}$-dependant templating effect reported in this manuscript. 


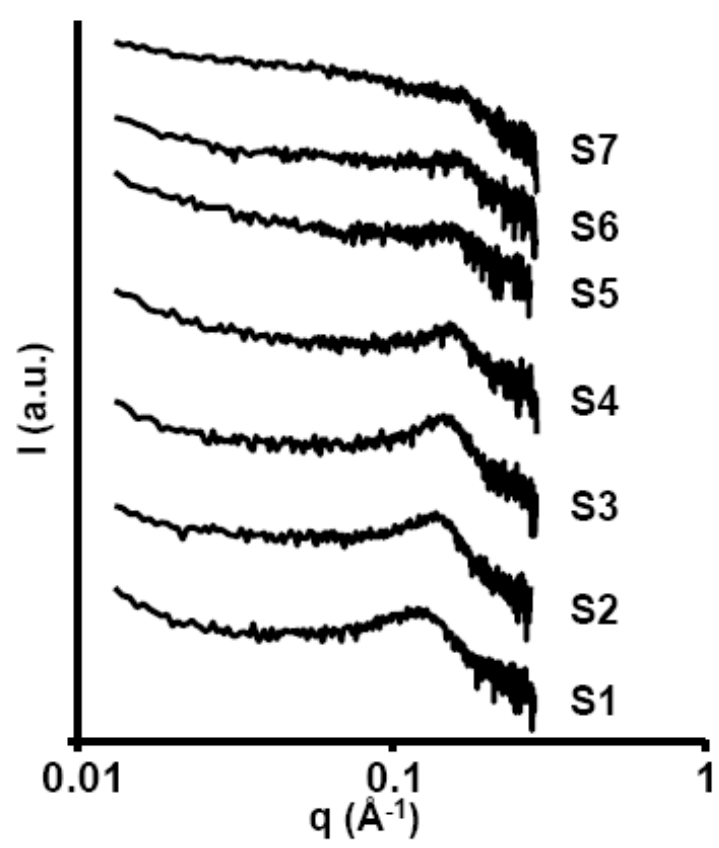

Figure 2 - Log-log plot of the SAXS spectra recorded for non-calcined samples S1 to S7. The amount of SL increases from S1 (SL/TEOS=0.06) to S7 (SL/TEOS=0.14). pH of the solution is lower than 3, as no base has been added. Samples refer to the $\mathrm{NaOH} \_0$ column in Table 2.

The typical 2D GISAXS patterns related to non-calcined S1, S5 and S7 are shown in Figure 3a-c. The continuous ring in (a) confirms that the scattering pattern is typical of a wormlike mesophase. For S5, the overall quality of the scattering pattern is definitely poorer, even if its morphology (the signal is concentrated on the right and left-hand side of the beam stop) seems to indicate a possible micellar alignment perpendicular to the film surface. Finally, for S7, the mesophase is most likely lost as well as any pore micellar morphology. The corresponding integrated patterns (in $2 \theta$ scale) are shown in Figure S2a. 


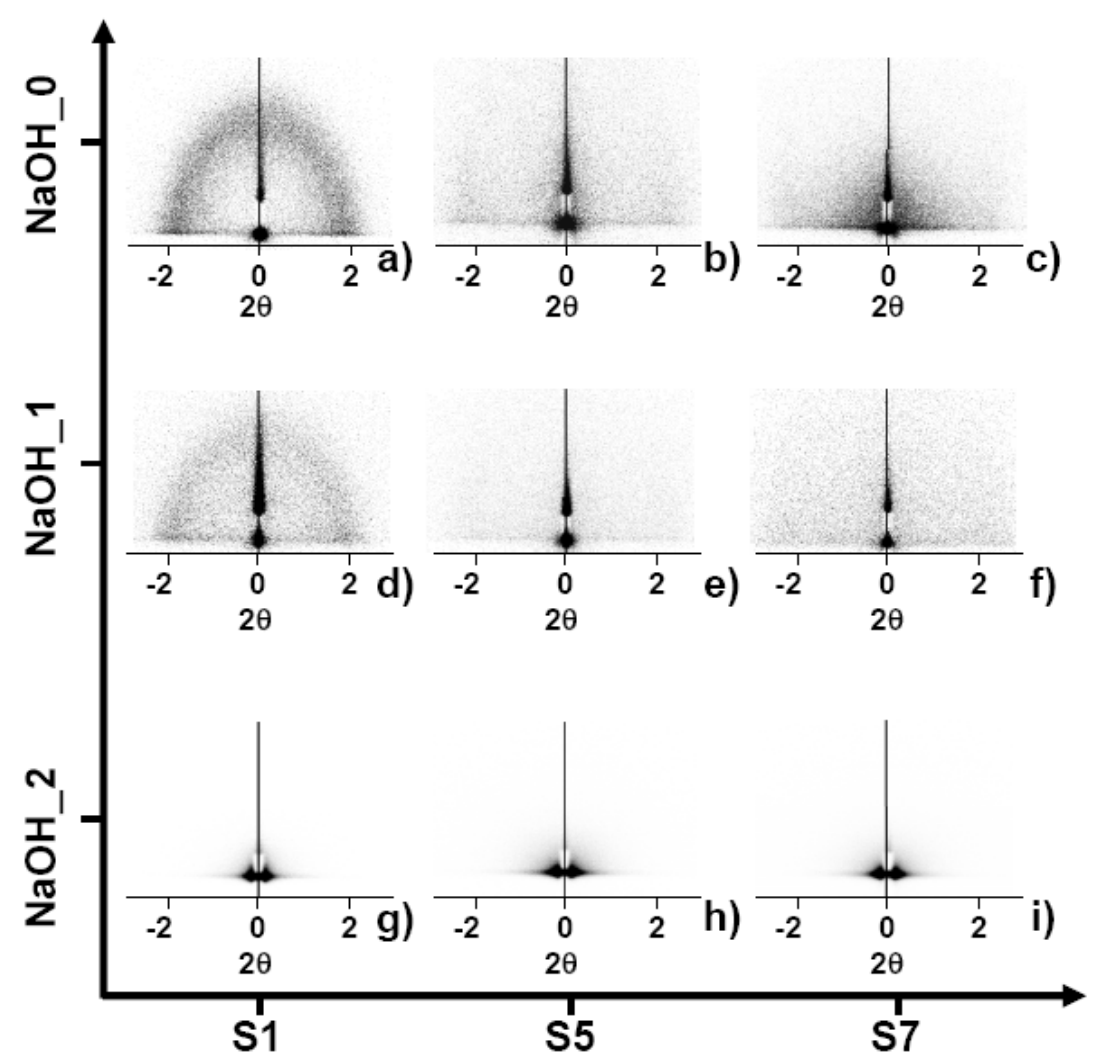

Figure 3 - Selected 2D SAXS patterns corresponding to non-calcined samples S1, S5 and S7. For the meaning of $\mathbf{N a O H} \_0, \mathbf{N a O H} \_1$ and $\mathrm{NaOH} \_2$ samples codes, please refer to

Table 2.

The Effect of Base Addition. The effect of $\mathrm{pH}$ on the mesostructure is shown on Figure 3d-i, while the corresponding integrated spectra are presented on Figure S2c-h. For all samples, the addition of small amounts of $\mathrm{NaOH}\left(\mathrm{NaOH} \_1\right.$ in Table 2) has a modest influence on the initial mesoscopic order (Figure 3d - Figure 3f), when compared to the corresponding, basefree, patterns (Figure 3a - Figure 3c). The same conclusion can be drawn by looking at the corresponding 1D integrated spectra on Figure S2c, 4e, 4g exception made for the S7 sample (red line, Figure S2g), for which low-q scattering is completely disrupted. This indicates that the small amount of base affects the constitution of the micro-scale channels. A six to ten fold (see Table 1 for molar ratios related $\mathrm{NaOH}_{-} 2$ ) increase in the base has, on the contrary, an important effect on all samples. Interestingly, this effect has similar consequences on the 
GISAXS patterns (Figure 3g-i), which show the complete disruption of the micellar network in favor of a strong signal very close to the center of the beam. Even if the amount of base required to observe this phenomenon slightly differs from S1 with respect to both S5 and S7 (Table 1), the same effect is observed from a NaOH/SL $>0.5$. This correlates well with our previous investigations concerning the effect of the ionization degree of the $\mathrm{COOH}$ group on the self-assembly of SL in water. ${ }^{31}$ In fact, at low ionization degrees $\left(\mathrm{COO}^{-} / \mathrm{COOH}\right), \mathrm{SL}$ forms ellipsoidal micelles ${ }^{32}$ with typical size of few nanometers. Upon full ionization of the $\mathrm{COOH}$ group, the system also forms large micronic, ill-defined, assemblies, as also shown by DLS data in the discussion section of this paper. In this study, the theoretical ionization degree estimated from the $\mathrm{NaOH} / \mathrm{SL}$ molar ratio given in Table 2 is below 0.3 for all NaOH_1 samples while that increases above 0.5 in the $\mathrm{NaOH} \_2$ samples. Even if the parallelism between the work in ref. 31 and this one is not possible due to at least two important factors (presence of ethanol, silica condensation is catalyzed by the presence of $\mathrm{NaOH}$ ), the presence of larger amount of base clearly has a strong effect on the final structuration and pore size distribution, as preliminary shown here by GISAXS and confirmed later on by microscopy and porosimetry analysis.

To better understand the origin of the intense signal at low angle observed in Figure 3 g-i, we draw the attention on the corresponding $1 \mathrm{D}$ integrated patterns on the right-hand side of Figure S2 (b,d,f,h), where the only the $0^{\circ}<2 \theta<2^{\circ}$ region is highlighted and where the Yscale is fully shown. In (b), the direct x-ray beam is detected at $2 \theta<0.15^{\circ}$ in the base-free reference systems. This is still the case for the SAXS experiments recorded under the NaOH_1 conditions (red pattern in d, f, h). For larger base amounts (blue patterns, NaOH_2), an additional intense peak is detected at $2 \theta>0.15^{\circ}$, which corresponds exactly to the lowangle diffusion just described in the 2D patterns (Figure 3). Since the position of this peak is invariant for all samples, one can deduce that it is not directly related to a well-defined 
correlation distance but rather to a strong, ultra low-angle scattering effect detected close to the beam stop. In fact, the lowest q-value in the SAXS apparatus used here is about $q=0.013$ $\AA^{-1}$, which identifies a typical size of about $48 \mathrm{~nm}(\mathrm{~d}=2 \pi / \mathrm{q})$. However, Figure S2 shows that important low-angle scattering already starts at typical sizes slightly above $15 \mathrm{~nm}$. This shows that the to low-angle scattering contains the contribution of all pores larger than about $15 \mathrm{~nm}$, as verified hereafter by TEM and SEM analysis.

Analysis of the Pore Size at Large $\mathrm{NaOH} / \mathrm{SL}>0.5$ Figure 4 shows the SEM images of samples S1, S5 and S7 in the $\mathrm{NaOH} \_2$ regime $(\mathrm{NaOH} / \mathrm{SL}>0.5)$, which is the one presenting the largest influence of base onto porosity. For all samples, the surface of the silica films shows an open porous texture, the pore size and interconnectivity of which strongly varies with the initial amount in SL. For S1, pores are estimated to be $220 \pm 70 \mathrm{~nm}$. For S5, we measure larger pores with a broader distribution (500 $\pm 200 \mathrm{~nm}$ ) while for S7, the pore size ranges in the $1.5 \pm 1.0 \mu \mathrm{m}$. In this last sample, the interconnection between pores seems extremely large if compared to S1 and S5. Additional SEM images at different scales for the same samples are provided in Figure S3 (a,b: S1; b,c: S5; d,e: S7), thus showing the extension and full coverage of the whole porous silica network over the silicon substrate. In the case when no base is added (images not shown), SEM is useless to characterize the silica thin film because this is constituted by a uniform flat surface. EDAX analysis for sample S7 combined with filtering for the Ka edge of oxygen confirms that the interconnected network visible on the SEM images is actually composed of $\mathrm{SiO}_{2}$ (purple box in Figure 4d). 

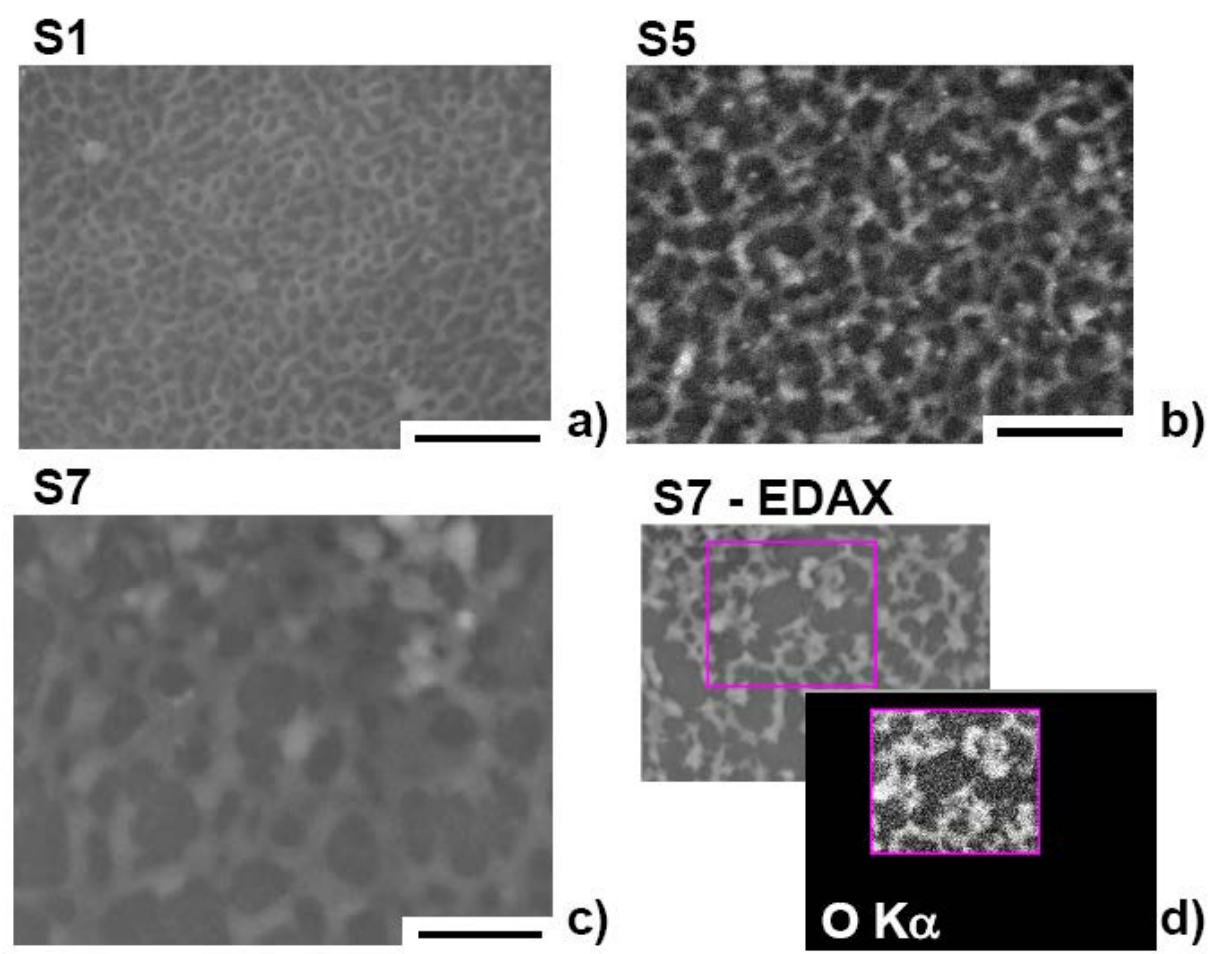

Figure 4 - SEM images recorded for samples (a) S1, (b) S5 and (c) S7 at large amounts of base (NaOH_2 system). (d) EDAX analysis (oxygen Ka edge) for S7 (NaOH_2). Scale bar $=2 \mu \mathrm{m}$

If SEM nicely shows the effect of base addition on the surface texture of the silica films, TEM can bring additional information on the eventual porosity inside the silica walls, as shown in Figure 5, where we only selected samples S1 and S5. In the base-free systems, (images a and d), a mesoporous structure is observed in the S1 sample, as already suggested by the GISAXS patterns discussed in Figure 3, while, as expected, the organization is more difficult to detect for S5. Upon addition of the base $\left(\mathrm{NaOH} \_2\right)$, TEM shows two families of pore distribution for sample S1. In (b), one finds spherical pores in the $100 \mathrm{~nm}$ range, which correlate well with SEM data, but a lower-scale porosity in the $10-20 \mathrm{~nm}$ range is also detected underneath the silica surface, as pointed out in the higher magnification image in (c). No small organized mesopores, possibly related to the presence of micelles, are indeed found, which also confirms the GISAXS data for this sample. Similar results are obtained for the base-treated S5 
sample (images e and f), where unorganized porosity in the 5-20 $\mathrm{nm}$ range is also observed. Additional TEM images for both S1 and S5 samples shown in Figure S4 confirm this description.

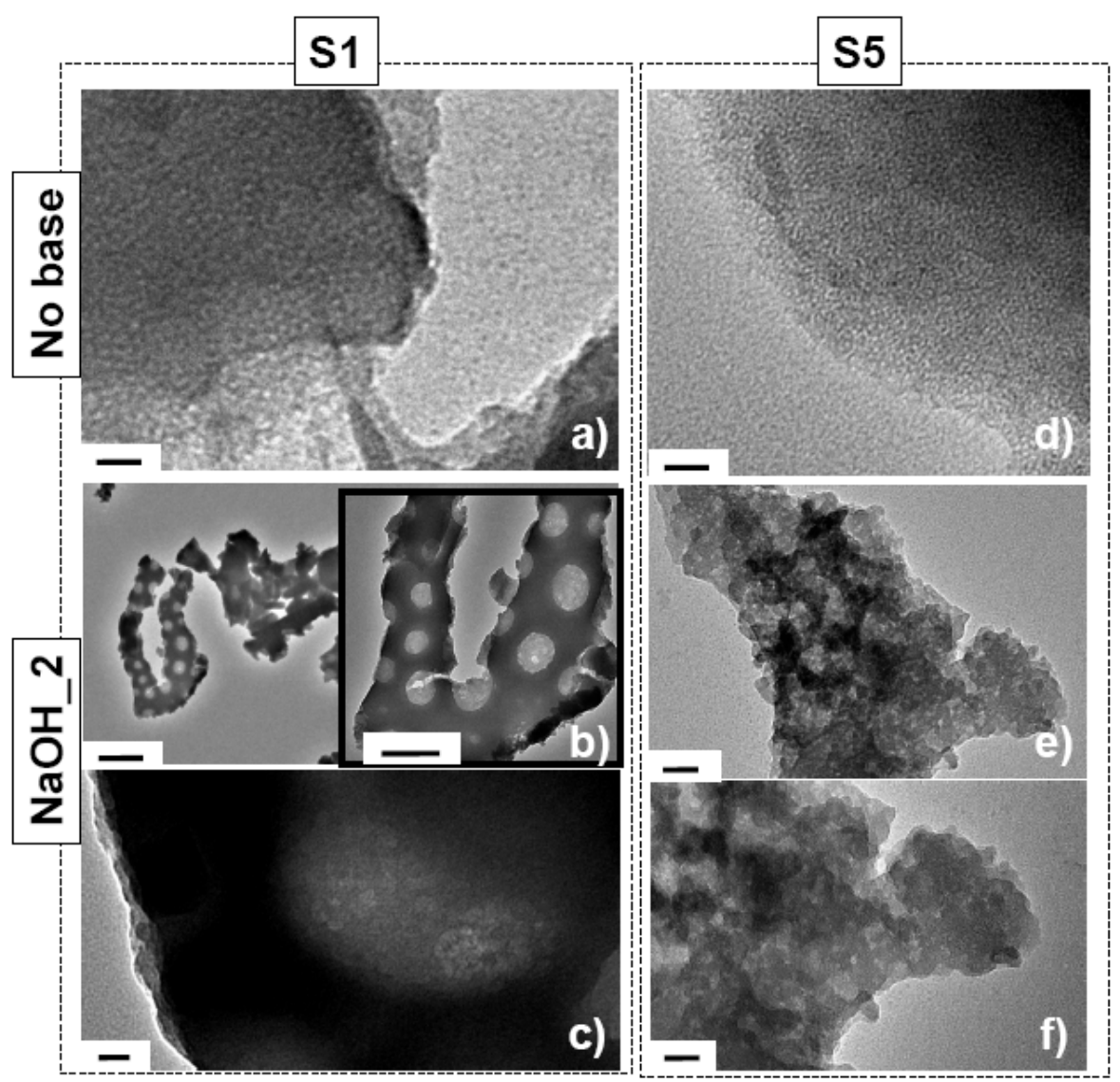

Figure 5 - TEM images recorded for samples (a-c) S1 and (d-f) S5 without base added and in the NaOH_2 system. Scale bars: a,d) $25 \mathrm{~nm}$, b) $1 \mu \mathrm{m}$; b-inset) $0.2 \mu \mathrm{m}$; e) $50 \mathrm{~nm}$; c,f) $20 \mathrm{~nm}$

More specific porosimetry experiments, performed by following the variation of the silica thin film refraction index (measured using ellipsometry) as a function of the relative humidity, $\mathrm{RH} \%$, support the data above and contribute to better describe the porous network of these materials (refer to Table 3 for numerical values). The adsorption-desorption isotherms recorded for samples S1, S5 and S7 under the $\mathrm{NaOH} \_0, \mathrm{NaOH} \_1$ and $\mathrm{NaOH}$ 2 conditions are shown on Figure 6 a-c, while the entire set of experiments is shown in Figure S5. When no 
base is added, isotherms are of type IVa, ${ }^{36,37}$ which is typical for interconnected pores heterogeneous in size and shape. Upon addition of small amounts of base (NaOH_1 in Figure S5), the nature of the isotherm does not change. On the contrary, in the NaOH_2 systems (Figure $6 \mathrm{a}-\mathrm{c}$ ), isotherms change completely and reflect the complex nature of the porous network. In all cases, the H4 hysteresis loop seems the best suited to describe the desorption behaviour. The capillary condensation occurs in the $0.7<\mathrm{P} / \mathrm{P}_{0}<0.8$ range, where nominal values increase consequently between S1 and S7. A second capillary condensation is also detectable above $\mathrm{P} / \mathrm{P}_{0}=0.9$, which is due to the presence of macropores. This last sample displays a well characteristic desorption branch, most likely typical of an array of slit-shaped pores in the microporous range. The double desorption step below $\mathrm{P} / \mathrm{P}_{0}=0.2$ may actually not be related to the simple pore emptying but to specific water adsorption phenomena which depend either on the surface chemistry or the roughness of the material. ${ }^{36}$ The pore size distributions calculated from the adsorption branches are shown in Figure 6 d-f. The S1 sample shows a relatively narrow distribution with respect to S5 and S7, which reflects the better mesoscale order observed by SAXS experiments. A common feature for all samples is the increase in pore size upon addition of the base. For NaOH_1, pore diameter is smaller than about $4 \mathrm{~nm}$. Additional increase in the base for S5 and S7 (not shown here) induce a further increase in diameter up to $6 \mathrm{~nm}$. Then, in the $\mathrm{NaOH} \_2$ systems and for all samples, the pore size is much broader and it reaches the values of $8 \mathrm{~nm}$ for S7.

The thickness of the silica films can be calculated from the ellipsometry data. Without base addition, thickness goes from $127 \mathrm{~nm}$ for S1 to $187 \mathrm{~nm}$ for S7 (Table 3 and Figure S6). This trend can most likely be related to a supposed increase in the solution viscosity due to the larger glycolipid amount. Upon base addition, the thickness systematically increases for all samples, a fact that could reasonably be explained by the increased viscosity of the sol-gel solution due to quicker based-catalyzed silica condensation. The direct proportional 
relationship between viscosity and thickness is well described by the Landau-Levitch equation $^{38}$ for non-evaporating fluids. The case of evaporating fluids in a withdrawal regime above $1 \mathrm{~mm}^{-1}$ for sol-gel-based thin films, a situation which best describes our systems, has been discussed in ref. 39, where authors also comment the effect of surfactant concentration and silica condensation rate on thickness.

In this work, the thickest sample is about $200 \mathrm{~nm}$ (S5 and S7) while the thinnest is $137 \mathrm{~nm}$ (S1), values which are quite common for mesoporous silica films obtained from blockcopolymer (Pluronic F127) surfactants at pulling rates of about $1 \mathrm{~mm} \cdot \mathrm{s}^{-1}{ }^{39}$ Additional interesting aspects on the thin film stability can also be deduced from the ellipsoporosimetry data. The variation of the thickness with relative humidity, RH\%, tells about the mechanical stability of the film; in fact, it has been shown that capillary condensation due to water adsorption in mesopores is responsible for strong local pressure with values of young modulus up to several GPa. ${ }^{33}$ If, at the end of each humidity cycle, the initial thickness is unvaried (or it has varied little), then the film has kept its structural integrity. This is the case for the sophorolipids' templated thin films shown in this study, as presented in the thickness vs. RH\% curves shown in Figure S6 for selected samples: in all cases, there is no considerable variation in the initial thickness upon a cycle. In comparison, silica thin films templated by classical cationic (CTAB) or block-copolymer (F127) surfactants are mechanically less stable, because the original thickness cannot be fully recovered after a single humidity cycle, ${ }^{33}$ thus making these materials more resistant to local stress than samples with monomodal longrange ordered mesoporosity.

The homogeneity of the mesopores inside the films can also be commented. In fact, the model used for fitting the experimental data required only one layer for achieving a good simulation, whatever the value of the relative humidity. This proves that no significant variations of the optical properties exist as a function of the depths of films, the resolution of which is better 
than $10 \mathrm{~nm} .{ }^{33}$ These arguments are also supported by the fact that the probed surface is 27 $\mathrm{mm}^{2}$ (size of the light beam: $9 \mathrm{~mm} \times 3 \mathrm{~mm}$ ), a dimension which is more than satisfactorily larger than any local lack in homogeneity at the nano and micro scale.

S1
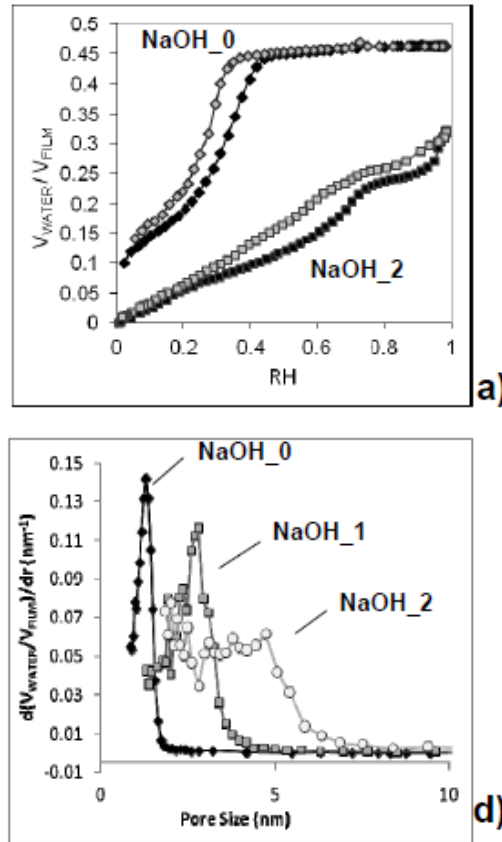

S5
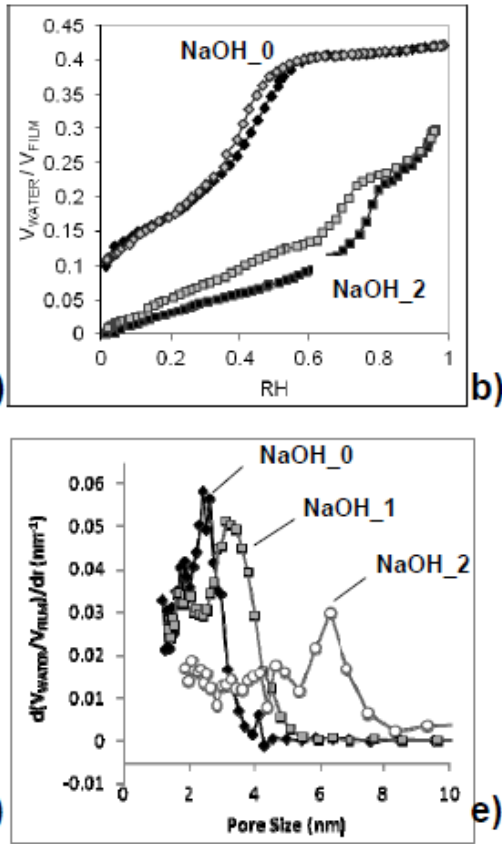

S7

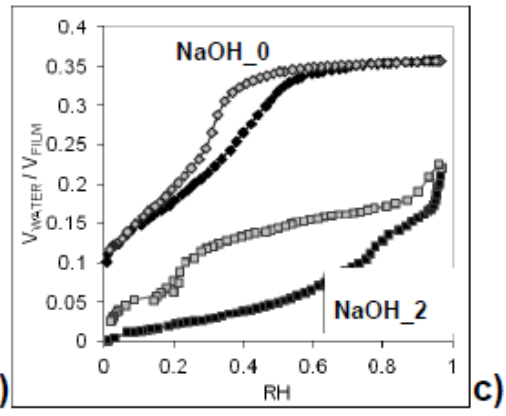

c)

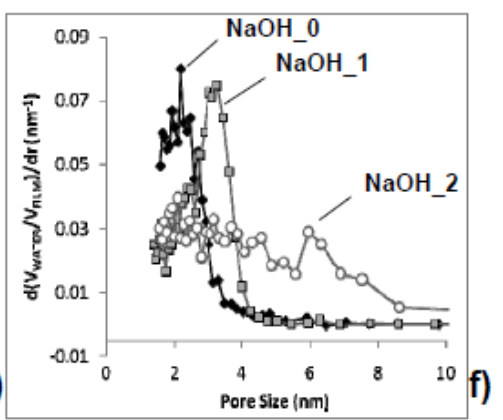

Figure 6 - (a-c) Water adsorption-desorption isotherms measured using ellipsoporosimetry for samples S1, S5, S7 in the NaOH_0 (base-free; all curves are manually shifted by 0.1 for sake of clarity) and $\mathrm{NaOH} \_2$ conditions. The full set of data is provided in Figure S5. (d-f) Pore size distribution calculated from the adsorption branch of the isotherms for samples S1, S5 and S7 in the NaOH_0, NaOH_1 and NaOH_2 conditions.

Table 3. Structural Features (average pore size, type of mesoptaining (NaOH_1, NaOH_2) Conditions EP: ellipsoporosimetryhase, film thickness) for Samples S1, S5 and S7 under Base-Free (NaOH_0) and Base-Con

\begin{tabular}{|c|c|c|c|c|c|c|c|c|c|}
\hline \multirow{2}{*}{$\begin{array}{c}\text { Structural } \\
\text { features }\end{array}$} & \multicolumn{3}{|c|}{ S1 } & \multicolumn{3}{|c|}{ S5 } & \multicolumn{3}{|c|}{ S7 } \\
\hline & $\mathrm{NaOH} 0$ & $\mathrm{NaOH} 1$ & $\mathrm{NaOH} 2$ & $\mathrm{NaOH} 0$ & $\mathrm{NaOH} 1$ & $\mathrm{NaOH} 2$ & $\mathrm{NaOH} O$ & $\mathrm{NaOH} 1$ & $\mathrm{NaOH} 2$ \\
\hline $\begin{array}{c}\text { Mesophase } \\
\text { (SAXS) }\end{array}$ & Wormlike & $\begin{array}{c}\text { Poorly } \\
\text { ordered }\end{array}$ & No order & Poor & Poor & No order & No order & No order & No order \\
\hline $\begin{array}{l}\text { Thickness } \\
\text { (nm) } \\
\text { (EP) }\end{array}$ & 127 & 128 & 137 & 152 & 166 & 202 & 187 & 200 & 197 \\
\hline Mesopores & $1.5-2$ & $3.5-4$ & $3-6$ & $2-3$ & $3.5-4$ & $3-8$ & $2-3$ & $3.5-4$ & $3-8$ \\
\hline
\end{tabular}


$(<10 \mathrm{~nm})$

(EP)

Mesopores

(<50 nm)

(TEM)

Macropores

$(\mu \mathrm{m})$

(SEM)
Ye

$0.2 \pm$

0.08
Yes

$0.5 \pm 0.2$
?

$1.5 \pm 1.0$

\section{DISCUSSION}

The experiments presented above show that the basic medium contributes to change the local structure of the silica network promoting the formation of a distribution of micro-meso- and macropores between $1.5 \mathrm{~nm}$ and $1 \mu \mathrm{m}$, whereas the calculated size of the SL molecule is not larger than $2.5 \mathrm{~nm} .{ }^{31}$ If we compare the results found here with the known porogenic mechanisms summarized in Table 1 , one can realize that none of those fully explain our results. First of all, our macroscale porosity cannot be related to the presence of colloidal particles, as we neither introduce nor form any. Neither can the surface porosity be related to the presence of other organic templates, such as large block copolymers, like polybutadieneb-polyethyleneoxide, which is known to produce organized cavities in the meso-macro limit range perpendicularly oriented to the film surface. ${ }^{40}$ Another hypothesis could be the formation of "breath figures", driven by water condensation at the film surface. ${ }^{19,20}$ However, this phenomenon would be difficult to explain because it is known to occur when water is mixed with a highly volatile solvent, like chloroform or THF. Two factors make us exclude this hypothesis, at least the way it is actually explained in the literature: 1) we do not have a highly volatile solvent, but only ethanol; 2) The size of the surface pores found here increases with the amount of employed SL (Table 3), while in general that is relatively independent of the concentration in organic matter (polymer, surfactant). The only exception occurs for very low concentration, at which the amount of compound is not enough to stabilize the water droplets. ${ }^{19}$ Additionally, we do not observe micronic surface porosity at acidic $\mathrm{pH}$ values for 
the same SL concentration, which strengthens the hypothesis that they cannot be related to the ethanol/water mixture. If we exclude all other hypotheses which obviously do not apply to our system (templating by ice, gas and salt), there are two last possible explanations.

Many authors have reported the formation of micronic surface patterns by exploiting phase separation effects induced by polymers (PEG, PPG, PLA). ${ }^{7,16,17,41}$ This method is very effective to make crack-free nested meso- and macropores, with diameters controllable in the 10-200 nm range. ${ }^{7,17}$ The proposed mechanism for PEG and PPG-templated $\mathrm{TiO}_{2}$ thin films involves the formation of a stable complex between the ethylene glycol units and the Ti-oxo clusters, where the macropores would then be directly linked to the phase separation of the solvent. ${ }^{42,43}$ Similar effects were obtained for the synthesis of bulk porous monolith in $\mathrm{SiO}_{2} / \mathrm{PEG}^{44,45}$ systems and have been explained via a so-called "chemical cooling”, as opposed to physical cooling; in the latter, macroscopic phase separation (the two-phase region) is achieved by cooling down the system temperature while in the former molecular movements are restrained by increasing the number of chemical bonds. Chemical cooling has been largely discussed in sol-gel systems. ${ }^{46}$ If some key elements found in chemical cooling are lacking from this study, such as polymers and/or additional solvent (besides water and ethanol), this mechanism was reported for other systems composed of $\mathrm{SiO}_{2} / \mathrm{CTAB} .{ }^{47}$ Whether this mechanism applies or not to the system studied here, it cannot be excluded, even if it is still uncertain for the following reasons: 1/ Chemical cooling has been largely described for the formation of monoliths, where evaporation of the solvent is slow, which is not the case for fast-evaporating systems composed of silica thin films; 2/ a large literature exists on the synthesis of porous silica thin-films (some examples given in Table 1) but much fewer (e.g., ref. 7 could be considered as one but the largest pores are much smaller than $1 \mu \mathrm{m}$ ) examples are reported on the use of chemical cooling on surfactant-based systems, for which the formation of breath figures is a most common mechanism; 3/ in the $\mathrm{SiO}_{2} / \mathrm{CTAB}$ porous 
monolith discussed in ref. 47, only two ranges of pores have been reported, $2 \mathrm{~nm}$ and $>1 \mu \mathrm{m}$, respectively corresponding to the size of CTAB micelles and phase separation effects while here we experience the formation of pores larger than $10 \mathrm{~nm}$; 4/ in chemical cooling, it exists an inverse proportionality between the amount of non-volatile organic compound (e.g., PEO, CTAB) and macropore size $\mathrm{e}^{47,48}$ and a direct one between the amount of solvent and macropore size. ${ }^{46}$ This is not the case for our system, where the macropore size increases from sample S1 to S7, that is, with the amount of sophorolipid in solution (Table 3).

Without excluding completely the chemical cooling hypothesis, we propose another mechanism. Sophorolipids in water under acidic $\mathrm{pH}$ conditions form micelles, but upon $\mathrm{pH}$ increase, in particular at low concentrations, micronic assemblies can also be formed, ${ }^{31,32}$ as shown by complementary DLS experiments shown in Figure S7.. Even if some caution must be employed when comparing the behavior of sophorolipids in pure water and in the presence of silica, ethanol or during the EISA process, one can still argue that these aggregates could be responsible for the pore size above $5 \mathrm{~nm}$ observed on samples S1, S5 and S7 studied here. For the largest, micron-sized, porosity, other wettability effects must probably be considered. To go further and test the wettability effect of a SL in water, we prepared a solution containing $\mathrm{SL}$ at a $\mathrm{NaOH} / \mathrm{SL}=1$; this was used to coat a silicon substrate and the corresponding SEM images are shown in Figure 7c,d. Interestingly, large micronic aggregates, which correspond to the bright texture in (c) (for sake of clarity, colors have been artificially inversed with respect to the original image), are observed and actually look closely to typical dewetting patterns found in other surfactant-based systems. ${ }^{49}$ Coating of a silicon substrate at $\mathrm{NaOH} / \mathrm{SL}=0$ results in a homogeneous thin film with no dewetting phenomenon. The EDAX analysis of the surface patterns is given in (d): the full analytical spectrum shows the presence of the following elements: silicon (from the substrate only), carbon and oxygen (from SL but also from impurities) and sodium (from the $\mathrm{NaOH}$ base solution). Even if 
EDAX should be used carefully when analyzing carbon and oxygen, the K $\alpha$ edge of carbon (in red) describes very well the texture (bright signal) observed in its corresponding SEM image. For completeness, we also provide the corresponding $\mathrm{K} \alpha$ edge of oxygen (in green), which, on the contrary, results to be less probing than the carbon edge.
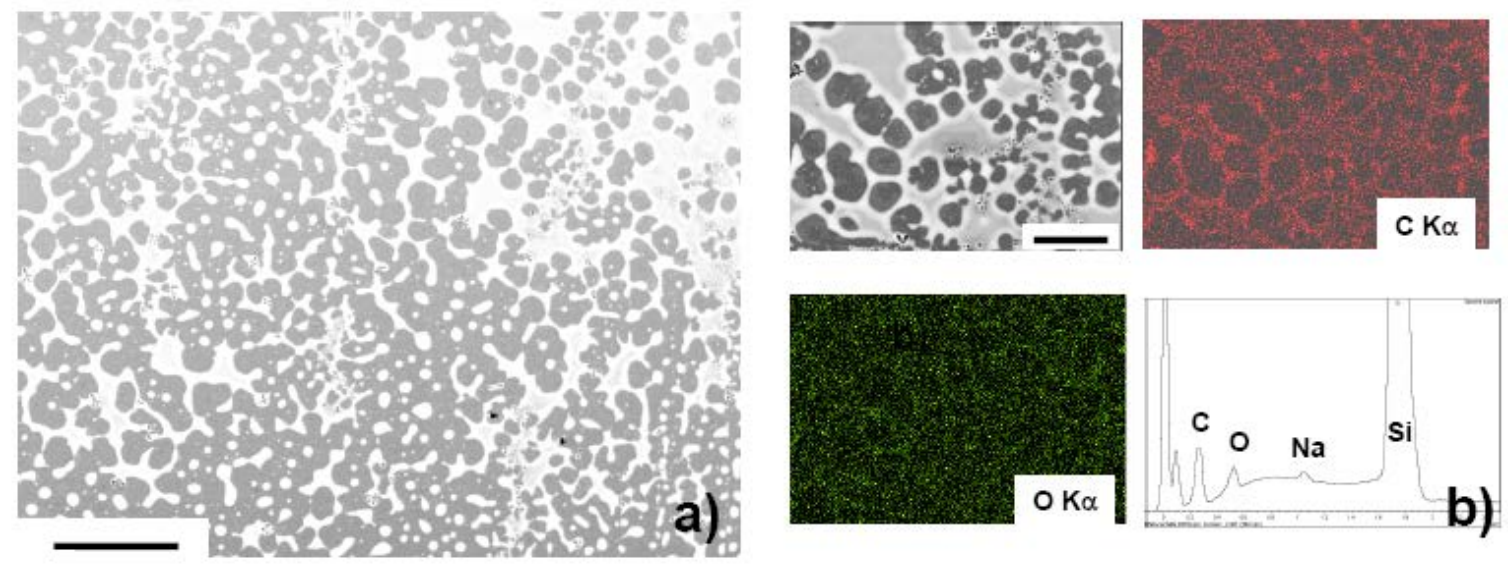

Figure 7. (a) SEM image of the $5 \mathrm{mg} / \mathrm{mL} \mathrm{SL}$ in water solution at $\mathrm{NaOH} / \mathrm{SL}=1\left(\right.$ no $\left.\mathrm{SiO}_{2}\right)$ deposited on a silicon substrate via the dip-coating process. (b) EDAX whole spectrum and 2D cartographic analysis ( $\mathrm{C} \mathrm{K \boldsymbol { \alpha }}$ and $\mathrm{O} \mathrm{K} \boldsymbol{\alpha}$ edges) of the same sample presented in (a). Scale bars: a) $50 \mu \mathrm{m}$; b-top left) $20 \mu \mathrm{m}$

Considering these data, we can formulate several hypotheses in terms of the mechanism of formation of the multiscale porosity for the SL-templated $\mathrm{SiO}_{2}$ films under basic conditions. In the first one, these assemblies constitute the direct template for silica at all scales. For pore size below $50 \mathrm{~nm}$, it is possible that SL aggregates observed in DLS constitute the template while for pore size above $500 \mathrm{~nm}$, the peculiar SL/surface interaction giving rise to the patterns in Figure 7c, 8d could be the porogenic driving force. In the second hypothesis, a possible phase separation mechanism as described above for the $\mathrm{TiO}_{2} / \mathrm{PEG}$ materials may occur where silica oligomers strongly interact with the micronic sophorolipid aggregates, thus repelling the solvent (water/ethanol) outside. Finally, a third, cooperative, effect could take 
place, where the solvent evaporation rate and the relative humidity in the dip-coating chamber could have important effect on water condensation effects at the film surface, thus making an atypical "breath-figure”-like mechanism.

The poor knowledge about the origin and stability in water ${ }^{32}$ (and even less in a water/ethanol mixture) of the supramolecular SL assemblies makes any possible clear-cut explanation hardly feasible. However, we believe that there seems to be a strong correlation between them and the multiscale, hierarchical, porosity and for this reason we make the first hypothesis highly possible. In this context, the second hypothesis, that is the formation of strong silica/SL interactions, could justify the micronic-scale surface pattering. For the third one, we do not believe that "breath figures" do actually form in the way they have been explained so far in the literature (no highly volatile solvent is used in this work) but relative humidity, not studied here, in the dip-coating chamber could probably plays an important role on water evaporation rates and its influence on the micronic-scale porosity.

\section{CONCLUSIONS}

In this work we show how a biobased functional glycolipid surfactant can be efficiently used to introduce a micro-to-macro scale porosity in a single step in EISA-processed silica thin films, without using co-solvents and co-surfactants. When prepared in solution under acidic conditions, sophorolipids (SL) form micelles that are able to form a mesoscale wormlike porosity, the typical size of which (about $2 \mathrm{~nm}$ ) is compatible with the typical size of the sophorolipid chain length. Upon addition of a strong base to the initial solution and keeping the same SL concentration, one can increase the pore size up to $4 \mathrm{~nm}$ but, beyond an upper threshold which depends on the initial SL concentration, large mesopores (8-30 nm) and macropores $(0.15-2 \mu \mathrm{m}$, according to the initial SL amount) are immediately formed. The former are interconnected within silica while the latter are oriented perpendicularly to the 
support. Their size and interconnectivity is highly dependent from the initial SL concentration. SAXS data recorded at different SL and $\mathrm{NaOH}$ amounts and combined with elliproporosimetry, SEM and TEM experiments clearly show the textural properties and porous network of the sophorolipids's templated silica thin films. The fact that we neither use any co-surfactants (e.g., block copolymers) nor polymers (e.g., PEG, PPG) and (volatile) cosolvents (e.g., THF, chloroform), makes this process very atypical if compared to the existing methods to make thin films with hierarchical porosity and which generally combined more than one compound and/or porogenic strategy. At the same time, the explanation is not straightforward. It is known that, at low SL concentrations in bulk water, micelles, generally formed under acidic conditions, are mostly disrupted at high $\mathrm{pH}$. This phenomenon puts in evidence, at the same time, the formation of large, micronic, supramolecular assemblies, as reported elsewhere but presented again in this work using DLS experiments. We also show how the large assemblies formed at unitary $\mathrm{NaOH} / \mathrm{SL}$ ratios can be deposited on a silicon surface in the absence of both ethanol and silica precursors and that they form interesting surface patterns. In terms of the mechanism, we believe that pores below $50 \mathrm{~nm}$ are formed by direct SL templating, as also found for silica particles. For the micronic pores we exclude the existence of "breath figures" (no volatile solvent is used here) but we make the hypothesis that surface patterns actually form due to strong SL/silicates interactions, probably enhancing a dewetting effect rather than a chemical cooling process, even though this is not excluded.

\section{ACKNOWLEDGMENT}

The research leading to these results has received funding from the European Community's Seventh Framework Programme (FP7/2007-2013) under Grant Agreement No. Biosurfing/289219. We warmly thank Mohamed Selmane and Isabelle Genois (Laboratoire de 
Chimie de la Matière Condense de Paris, Collège de France/UPMC/CNRS, Paris, France) for their kind help with some of the experiments.

SUPPORTING INFORMATION DESCRIPTION. Figure S1: Log-log plot of the SAXS spectrum recorded for sample S7. Figure S2: Integrated SAXS patterns corresponding to samples S1, S5 and S7. Figure S3: SEM images of samples S1, S5 and S7 in the NaOH_2 conditions. Figure S4: TEM images of samples S1 and S5 in the $\mathrm{NaOH} 22$ conditions. Figure S5: Full set of ellipsoporosimetry data (isotherms and pore size distribution) for all samples. Figure S6: Evolution of the silica film thickness with relative humidity RH\%. Figure S7: DLS data recorded on pure SL in water solutions. This material is available free of charge via the Internet at http://pubs.acs.org

\section{REFERENCES}

${ }^{1}$ Qian, K. K.; Bogner, R. H. Application of mesoporous silicon dioxide and silicate in oral amorphous drug delivery systems J. Pharm. Sci. 2012, 101, 444-463

${ }^{2}$ Lee, J. E.; Lee, N.; Kim, T.; Kim, J.; Hyeon, T. Multifunctional Mesoporous Silica Nanocomposite Nanoparticles for Theranostic Applications Acc. Chem. Res. 2011, 44, 893902

${ }^{3}$ Slowing, I. I.; Vivero-Escoto, J. L.; Trewyn, B. G.; Lin, V. S. Y. Mesoporous silica nanoparticles: structural design and applications J. Mater. Chem. 2010, 20, 7924-7937 ${ }^{4}$ Innocenzi, P.; Malfatti, L.; Soler-Illia, G. J. A. A Hierarchical Mesoporous Films: From Self-Assembly to Porosity with Different Length Scales Chem. Mater. 2011, 23, 2501-2509 ${ }^{5}$ Meng, X.; Kimura, T.; Ohji, T.; Kato, K. Triblock copolymer templated semi-crystalline mesoporous titania films containing emulsion-induced macropores J. Mater. Chem. 2009, 19, $1894-1900$ 
${ }^{6}$ Yang; P.; Deng, T.; Zhao, D.; Feng, P.; Pine, D.; Chmelka, B. F.; Whitesides, G. M.; Stucky

G. D. Hierarchically Ordered Oxides Science 1998, 282, 2244-2246.

${ }^{7}$ Malfatti, L.; Bellino, M. G.; Innocenzi, P.; Soler-Illia, G. J. A. A. One-Pot Route to Produce Hierarchically Porous Titania Thin Films by Controlled Self-Assembly, Swelling, and Phase Separation Chem. Mater., 2009, 21, 2763-2769

${ }^{8}$ Sel, O.; Kuang, D.; Thommes, M.; Smarsly, B. Principles of Hierarchical Meso- and Macropore Architectures by Liquid Crystalline and Polymer Colloid Templating Langmuir 2006, 22, 2311-2322

${ }^{9}$ Brinker, C. J.; Lu, Y.; Sellinger, A.; Fan, H. Evaporation-Induced Self-Assembly: Nanostructures Made Easy Adv. Mater. 1999, 11, 579-585

${ }^{10}$ Grosso, D.; Cagnol, F.; Soler-Illia, G. J. A. A.; Crepaldi, E. L.; Amenitsch, H.; BrunetBruneau, A.; Bourgeois, A.; Sanchez, C. Fundamentals of Mesostructuring Through Evaporation-Induced Self-Assembly Adv. Funct. Mater. 2004, 14, 309-322

${ }^{11}$ Sel, O.; Sallard, S.; Brezesinski, T.; Rathousky, J.; Dunphy, D. R.; Collord, A.; Smarsly, B. Periodically Ordered Meso- and Macroporous SiO2 Thin Films and Their Induced Electrochemical Activity as a Function of Pore Hierarchy Adv. Funct. Mater. 2007, 17, 32413250.

${ }^{12}$ Li, X.; He, J. Superhydrophilic and Antireflective Properties of Silica Nanoparticle Coatings Fabricated via Layer-by-Layer Assembly and Postcalcination J. Phys. Chem. C, 2009, 113, 148-152

${ }^{13}$ Falcaro, P.; Malfatti, L.; Kidchob, T.; Giannini, G.; Falqui, A.; Casula, A. M. F.; Amenitsch, H.; Marmiroli, B.; Grenci, G.; Innocenzi, P. Hierarchical Porous Silica Films with Ultralow Refractive Index Chem. Mater. 2009, 21, 2055-2061 
${ }^{14}$ Heinroth, F.; Munzer, S.; Feldhoff, A.; Passinger, S.; Cheng, W.; Carsten, R.; Chichkov, B.; Behrens, P. Three-dimensional titania pore structures produced by using a femtosecond laser pulse technique and a dip coating procedure J. Mater. Sci. 2009, 44, 6490-6497

${ }^{15}$ Innocenzi, P.; Malfatti, L.; Marongiu, D.; Casula, M. F. Controlling shape and dimensions of pores in organic-inorganic films: nanocubes and nanospheres New J. Chem. 2011, 35, $1624-1629$

${ }^{16}$ Kajihara, K.; Nakanishi, K.; Tanaka, K.; Hirao, K.; Soga, N. Preparation of macroporous titania films by a sol-gel dip-coating method from the system containing poly(ethylene glycol) J. Am. Ceram. Soc. 1998, 81, 2670-2676

${ }^{17}$ Fuertes, M. C.; Soler-Illia, G. J. A. A. Processing of Macroporous Titania Thin Films: From Multiscale Functional Porosity to Nanocrystalline Macroporous TiO2 Chem. Mater. 2006, 18, 2109-2117

${ }^{18}$ Nishihara, H.; Mukai, S. R.; Yamashita, D.; Tamon, H. Ordered Macroporous Silica by Ice Templating Chem. Mater., 2005, 17, 683-689

${ }^{19}$ Maruyama, N.; Koito, T.; Nishida, J.; Sawadaishi, T.; Cieren, X.; Ijiro, K.; Karthaus, O.; Shimomura, M. Mesoscopic patterns of molecular aggregates on solid substrates Thin Solid Films 1998, 327-329, 854-856

${ }^{20}$ Sakatani, Y.; Boissière, C.; Grosso, D.; Nicole, L.; Soler-Illia, G. J. A. A.; Sanchez, C. Coupling Nanobuilding Block and Breath Figures Approaches for the Designed Construction of Hierarchically Templated Porous Materials and Membranes Chem. Mater. 2008, 20, 1049_ 1056

${ }^{21}$ Saunders, A. E.; Shah, P. S.; Sigman, Jr. M. B.; Hanrath, T.; Hwang, H. S.; Lim, K. T.; Johnston, K. P.; Korgel, B. A. Inverse Opal Nanocrystal Superlattice Films Nano Lett. 2004, 4, 1943-1948 
${ }^{22}$ Li, X. S.; Fryxell, G. E.; Wang, C.; Young, J. Nitrocellulose templated hierarchical pore structure in mesoporous thin films Inorg. Chem. Commun. 2006, 9, 7-9

${ }^{23}$ Baccile, N.; Babonneau, F.; Thomas, B.; Coradin, T. Introducing ecodesign in silica sol-gel materials J. Mater. Chem., 2009, 19, 8537-8559

${ }^{24}$ Gérardin, C. ; Reboul, J.; Bonne, M.; Lebeau, B. Ecodesign of ordered mesoporous silica materials Chem. Soc. Rev. 2013, 42, 4217-4255

${ }^{25}$ Rau, U.; Hammen, S.; Heckmann, R.; Wray, V.; Lang, S. Sophorolipids: a source for novel compounds, Ind. Crops Prod. 2001, 13, 85-92

${ }^{26}$ Tulloch, A. P.; Hill, A.; Spencer, J. F. T. Structure and reactions of lactonic and acidic sophorosides of 17-hydroxyoctadecanoic acid Canad. J. Chem. 1968, 46, 3337-3351

${ }^{27}$ Asmer, H.-J.; Lang, S.; Wagner, F.; Wray, V. Microbial production, structure elucidation and bioconversion of sophorose lipid J. Am. Oil. Chem. Soc. 1988, 65, 1460-1466

${ }^{28}$ Zhou, S.; Xu, C.; Wang, J.; Gao, W.; Akhverdiyeva, R.; Shah, V.; Gross, R. Supramolecular assemblies of a naturally derived sophorolipid Langmuir 2004, 20, 7926-7932

${ }^{29}$ Develter, D. W. G.; Fleurackers, S. J. J. Sophorolipids and Rhamnolipids. In Surfactants from Renewable Resources, Kjellin, M., Johansson, I., Eds.; John Wiley \& Sons: West Sussex, UK, 2010; pp 213-238.

${ }^{30}$ Baccile, N.; Nassif, N.; Malfatti, L.; Van Bogaert, I. N. A.; Soetaert, W.; Pehau-Arnaudet, G.; Babonneau, F. Sophorolipids: a yeast-derived glycolipid as greener structure directing agents for self-assembled nanomaterials Green Chem. 2010, 12, 1564-1567

${ }^{31}$ Baccile, N.; Babonneau, F.; Jestin, J.; Pehau-Arnaudet, G.; Van Bogaert, I. N. A. Unusual, pH-Induced, Self-Assembly Of Sophorolipid Biosurfactants ACS Nano 2012, 6, 4763-4776

${ }^{32}$ Baccile, N.; Pedersen, J. S.; Pehau-Arnaudet, G.; Van Bogaert, I. N. A. Surface charge of acidic sophorolipid micelles: effect of base and time Soft Matter, 2013, 9, 4911-4922 
${ }^{33}$ Boissiere, C. ; Grosso, D.; Lepoutre, S.; Nicole, L.; Brunet Bruneau, A.; Sanchez, C. Porosity and mechanical properties of mesoporous thin films assessed by environmental ellipsometric porosimetry Langmuir 2005, 21, 12362-12371

${ }^{34}$ Zhao, D.; Yang, P.; Melosh, N.; Feng, J.; Chmelka, B. F.; Stucky, G. D. Continuous Mesoporous Silica Films with Highly Ordered Large Pore Structures Adv. Mater. 1998, 10, 1380-1385

${ }^{35}$ Grosso, D.; Balkenende, A. R.; Albouy, P. A.; Ayral, A.; Amenitsch, H.; Babonneau, F. Two-dimensional hexagonal mesoporous silica thin films prepared from block copolymers : detailed characterization and formation mechanism. Chem. Mater. 2001, 13, 1848-1856 ${ }^{36}$ Gregg, S. J.; Sing, K. S. W. Adsorption, Surface Area and Porosity, Academic Press Limited: London, 1982

${ }^{37}$ Rouquerol, F.; Rouquerol, J.; Sing, K. Adsorption by Powders and Porous Solids: Principles, Methodology and Applications, Academic Press Limited: London, 1999 ${ }^{38}$ Landau, L.; Levich, B. Dragging of a liquid by a moving plate Acta Physicochim. URSS 1942, 17,42

${ }^{39}$ Faustini, M.; Louis, B.; Albouy, P. A.; Kuemmel, M.; Grosso, D. Preparation of Sol-Gel Films by Dip-Coating in Extreme Conditions J. Phys. Chem. C 2010, 114, 7637-7645

${ }^{40}$ Faustini, M.; Nicole, L.; Boissière, C.; Innocenzi, P.; Sanchez, C.; Grosso, D. Hydrophobic, Antireflective, Self-Cleaning, and Antifogging Sol-Gel Coatings: An Example of Multifunctional Nanostructured Materials for Photovoltaic Cells Chem. Mater. 2010, 22, 4406-4413

${ }^{41}$ Zhao, B.; Zhang, J.; Wang, X.; Li, C. Water-assisted fabrication of honeycomb structure porous film from poly(L-lactide) J. Mater. Chem. 2006, 16, 509-513 
${ }^{42}$ Kajihara, K.; Yao, T. Macroporous Morphology of the Titania Films Prepared by a Sol-Gel Dip-Coating Method from the System Containing Poly(Ethylene Glycol). I. Effect of Humidity J. Sol.-Gel Sci. Technol. 1998, 12, 185-192

${ }^{43}$ Kajihara, K.; Yao, T. Macroporous Morphology of the Titania Films Prepared by a Sol-Gel Dip-Coating Method from the System Containing Poly(Ethylene Glycol). II. Effect of Solution Composition J. Sol.-Gel Sci. Technol. 1998, 12, 193-201

${ }^{44}$ Nakanishi, K.; Komura, H.; Takahashi, R.; Soga, N. Phase Separation in Silica Sol-Gel System Containing Poly(ethylene oxide). I. Phase Relation and Gel Morphology Bull. Chem. Soc. Jpn. 1994, 67, 1327-1335;

${ }^{45}$ Nakanishi, K.; Soga, N. Phase Separation in Silica Sol-Gel System Containing

Poly(ethylene oxide) II. Effects of Molecular Weight and Temperature Bull. Chem. Soc. Jpn. 1997, 70, 587-592

${ }^{46}$ Nakanishi, K. Pore Structure Control of Silica Gels Based on Phase Separation J. Porous. Mater. 1997, 4, 67-112

${ }^{47}$ Nakanishi, K.; Sato, Y.; Ruyat, Y.; Hirao, K. Supramolecular Templating of Mesopores in Phase-Separating Silica Sol-Gels Incorporated with Cationic Surfactant J. Sol-Gel Sci.

Technol., 2003 26, 567-570

${ }^{48}$ Nakanishi, K.; Tanaka, N. Sol-Gel with Phase Separation. Hierarchically Porous Materials Optimized for High-Performance Liquid Chromatography Separations Acc. Chem. Res. 2007, 40, 863-873

${ }^{49}$ Bernardes, J. S.; Rezende, C. A.; Galembeck, F. Morphology and self-arraying of SDS and DTAB dried on mica surface Langmuir 2010, 26, 7824-7832 
TOC

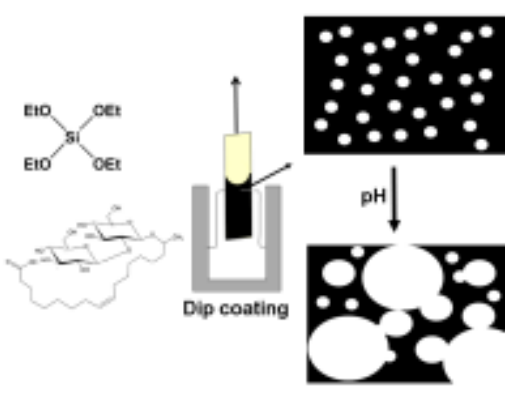

